\title{
Guanidinium and Mixed Cesium-Guanidinium Tin(II) Bromides: Effects of Quantum Confinement and Out-of-Plane Octahedral Tilting
}

Olga Nazarenko, ${ }^{\dagger}$ Martin R. Kotyrba, ${ }^{\dagger, \ddagger}$ Sergii Yakunin, ${ }^{\dagger, \ddagger \odot ~ M i c h a e l ~ W o ̈ r l e, ~}{ }^{\dagger}$ Bogdan M. Benin, ${ }^{\dagger, \ddagger}$

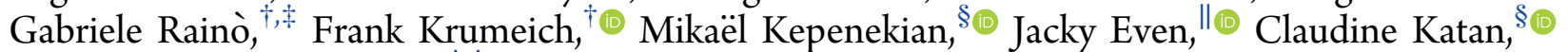
and Maksym V. Kovalenko ${ }^{\dagger,+* *(1)}$

\footnotetext{
${ }^{\dagger}$ Laboratory of Inorganic Chemistry, Department of Chemistry and Applied Biosciences, ETH Zürich, Vladimir-Prelog-Weg 1, CH-8093 Zürich, Switzerland

${ }^{\S}$ Univ Rennes, ENSCR, INSA Rennes, CNRS, ISCR (Institut des Sciences Chimiques de Rennes) - UMR 6226, F-35000 Rennes, France

"Univ Rennes, INSA Rennes, CNRS, Institut FOTON - UMR 6082, F-35000 Rennes, France

${ }^{\ddagger}$ Laboratory for Thin Films and Photovoltaics, Empa - Swiss Federal Laboratories for Materials Science and Technology, Überlandstrasse 129, CH-8600 Dübendorf, Switzerland
}

Supporting Information
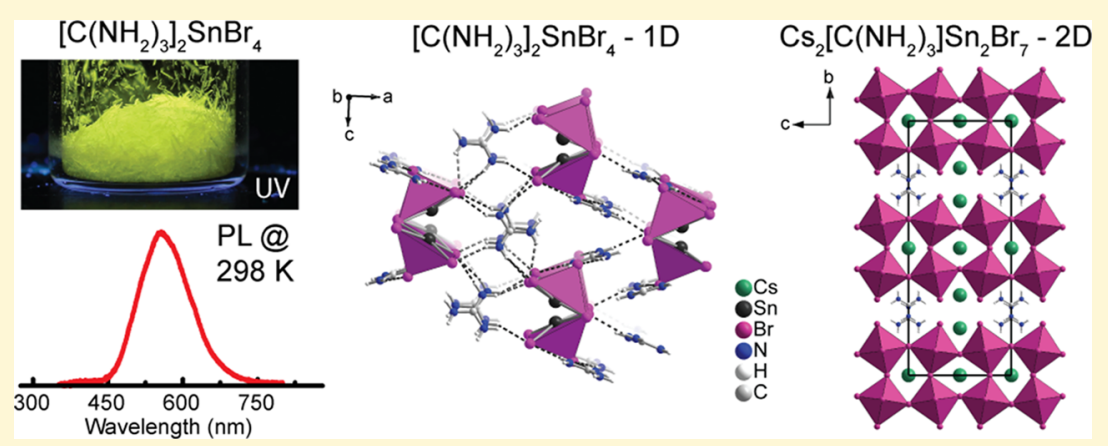

ABSTRACT: Hybrid organic-inorganic main-group metal halide compounds are the subject of intense research owing to their unique optoelectronic characteristics. In this work, we report the synthesis, structure, and electronic and optical properties of a family of hybrid tin (II) bromide compounds comprising guanidinium $\left[\mathrm{G}, \mathrm{C}\left(\mathrm{NH}_{2}\right)_{3}{ }^{+}\right]$and mixed cesium-guanidinium cations: $\mathrm{G}_{2} \mathrm{SnBr}_{4}, \mathrm{CsGSnBr}_{4}$, and $\mathrm{Cs}_{2} \mathrm{GSn}_{2} \mathrm{Br}_{7} . \mathrm{G}_{2} \mathrm{SnBr}_{4}$ has a one-dimensional structure that consists of chains of corner-sharing $\left[\mathrm{SnBr}_{5}\right]^{2-}$ square pyramids and $\mathrm{G}$ cations situated in between the chains. Cs ${ }^{+}$exhibits a pronounced structure-directing effect where a mixture of $\mathrm{Cs}^{+}$and $\mathrm{G}$ cations forms mono- and bilayered two-dimensional perovskites: $\mathrm{CsGSnBr}_{4}$ and $\mathrm{Cs}_{2} \mathrm{GSn}_{2} \mathrm{Br}_{7}$. Furthermore, the flat shapes of the guanidinium cations induce anisotropic out-of-plane tilts of the $\left[\mathrm{SnBr}_{6}\right]^{4-}$ octahedra in the CsGSnBr 4 and $\mathrm{Cs}_{2} \mathrm{GSn}_{2} \mathrm{Br}_{7}$ compounds. In $\mathrm{G}_{2} \mathrm{SnBr}_{4}$, the $\mathrm{Sn}$ lone pair is highly stereoactive and favors non-octahedral, that is, square pyramidal coordination of $\mathrm{Sn}(\mathrm{II}) . \mathrm{G}_{2} \mathrm{SnBr}_{4}$ exhibits bright broad-band emission from self-trapped excitonic states, owing to its soft lattice and electronic localization. This emission in $\mathrm{G}_{2} \mathrm{SnBr}_{4}$ is characterized by a photoluminescence (PL) quantum yield of $2 \%$ at room temperature $(\mathrm{RT} ; 75 \pm 5 \%$ at $77 \mathrm{~K}$ ) and a fast PL lifetime of $18 \mathrm{~ns}$ at room temperature.

$\mathrm{H}$ ybrid organic-inorganic tin (II) halide compounds are intensely researched due to their photophysics and electronic properties, which are all governed by the structural diversity of $\mathrm{Sn}$ (II) halide anionic networks. ${ }^{1-6}$ Such compounds are promising for application in light-emitting devices, ${ }^{6-8}$ solar cells, ${ }^{9,10}$ and photodetectors. ${ }^{11}$ The crystal structure of hybrid tin (II) halide compounds consists of $\mathrm{Sn}$ (II)-X (X = Cl, Br, I) coordination anionic networks and organic cations. $\mathrm{Sn}$ (II)-X units can arrange themselves into a vast variety of structures: from extended three-dimensional (3D) structures composed of $\mathrm{Sn}$ (II)-X coordination polyhedra connected by corners, edges, and faces to isolated polyhedral units (OD compounds) with a plethora of structures in between. ${ }^{1,3,12-16}$ The $S n(I I)-X$ units thus far observed experimentally include trigonal pyramids (coordination number, $\mathrm{CN}$, of 3$),{ }^{17,18}$ seesaws $(\mathrm{CN}=4),{ }^{6}$ square pyramids $(\mathrm{CN}=5),{ }^{5,19}$ and, most commonly, octahedral units $(\mathrm{CN}=6) .{ }^{1,20}$ The coordination geometry of the $\mathrm{Sn}(\mathrm{II})$ ion is a complex interplay that involves the effects of the stereoactivity of the 5 s lone pair as well as the geometry of the organic cation and the interactions of the cation with inorganic

Received: January 5, 2019

Revised: February 12, 2019

Published: February 13, 2019 


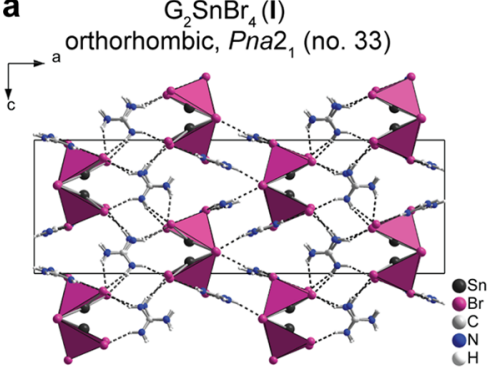

e

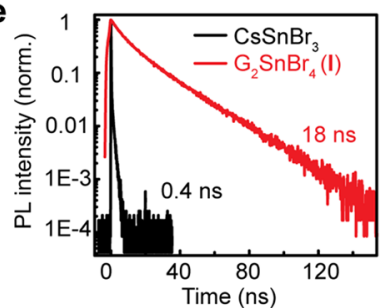

b
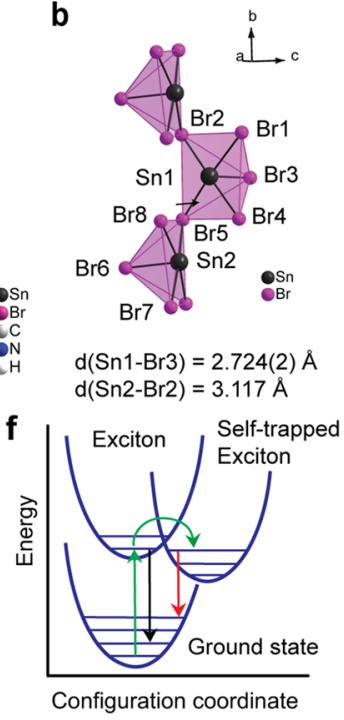

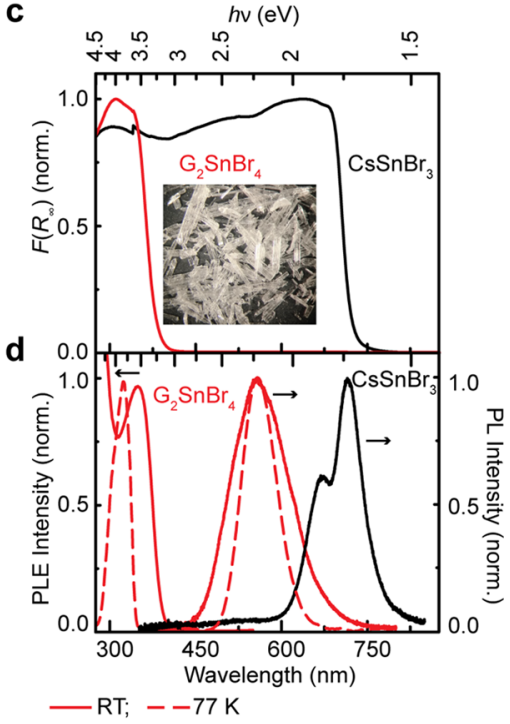

Figure 1. (a, b) Crystal structure of guanidinium tin bromide $-\mathrm{G}_{2} \mathrm{SnBr}_{4}(\mathrm{I})$. (c) Kubelka-Munk function $F\left(R_{\infty}\right)=\left(1-R_{\infty}\right)^{2} / 2 R_{\infty}\left(R_{\infty}\right.$ is diffusive reflectance) of $\mathrm{CsSnBr}_{3}$ and I. (d) Photoluminescence (PL) and PL excitation (PLE) spectra measured on powdered crystals of $\mathrm{CsSnBr}_{3}$ and $\mathrm{G}_{2} \mathrm{SnBr}_{4}$ (I). (e) Time-resolved PL traces of $\mathrm{CsSnBr}_{3}$ and $\mathbf{I}$ at room temperature (RT). (f) Schematic of the formation of self-trapped excitons.

units such as hydrogen bonding. Satisfactory rationalization (and prediction) of these effects on the atomistic and electronic structure of the resulting compounds remains a formidable challenge.

The electronic band structure of hybrid $\mathrm{Sn}$ (II) halide compounds at the band gap is formed mainly by $\mathrm{Sn} 5 \mathrm{p}$ and $5 \mathrm{~s}$ orbitals and halide $n p$ orbitals. Nonconjugated organic amines do not significantly contribute to frontier orbitals. ${ }^{21,22}$ In hybrid tin (II) halide perovskite structures, such as $\left(\mathrm{C}_{6} \mathrm{H}_{5} \mathrm{CH}_{2} \mathrm{CH}_{2} \mathrm{NH}_{3}\right)_{2} \mathrm{SnI}_{4}$, the $n \mathrm{~s}^{2}$ pair of $\mathrm{Sn}$ defines an antibonding character of the valence band maximum by coupling with the $p$ orbitals of halogen atoms. ${ }^{22}$ The band gap depends on the dimensionality and connectivity of the $\mathrm{Sn}$ (II)-X units, the atomic number of the halogen, and distortions of the metal halide polyhedra (governed by the organic moiety). ${ }^{1,2,23}$ For instance, the optical band gap of $3 \mathrm{D} \mathrm{CH}_{3} \mathrm{NH}_{3} \mathrm{SnI}_{3}$ is 1.26 $\mathrm{eV}$, whereas 2D $\left[\mathrm{C}_{6} \mathrm{H}_{5}\left(\mathrm{CH}_{2}\right)_{2} \mathrm{NH}_{3}\right]_{2} \mathrm{SnI}_{4}$ has an optical absorption edge at $1.97 \mathrm{eV}^{24}$

In the context of real-world applications, low-dimension hybrid Sn(II) halides might eventually be of use as bright light emitters for lighting and other applications. For instance, OD $\left(\mathrm{C}_{4} \mathrm{~N}_{2} \mathrm{H}_{14} \mathrm{Br}\right)_{4} \mathrm{SnBr}_{3} \mathrm{I}_{3}$ [organic cation is $N, N^{\prime}$-dimethylethylene-1,2-diammonium] demonstrates bright, yellow, broadband photoluminescence (PL) with a quantum yield (QY) of $\sim 85 \%$ and a large Stokes shift $(>100 \mathrm{~nm})$ and a full width of half maximum (FWHM) - $126 \mathrm{~nm}^{7}$ The corresponding compound, $\left(\mathrm{C}_{4} \mathrm{~N}_{2} \mathrm{H}_{14} \mathrm{Br}\right)_{4} \mathrm{SnBr}_{6}$, containing exclusively bromide exhibits a QY close to $100 \%{ }^{8}$ The structure of these compounds comprises $\mathrm{SnX}_{6}{ }^{4-}$ octahedra isolated by organic cations. Such emission characteristics are attributed to the emission from socalled self-trapped excitons, which are characterized by high binding energies and a low probability of interaction with intrinsic defects. ${ }^{25}$ Self-trapped excitons form due to a combination of electronic localization of an electron-hole pair (exciton) and structural distortion that occurs fast upon photoexcitation (Figure 1f), which lead to a Jahn-Teller-like distortion in the excited state. ${ }^{26}$ Hybrid OD main-group metal halides are characterized by a soft lattice, strongly favoring the formation of self-trapped excitons due to facile structural distortion (exciton-phonon coupling). Radiative relaxation of self-trapped excitons leads to broad-band emission with a large Stokes shift as reported recently for a wide range of $\mathrm{Sn}$ (II) and $\mathrm{Sb}$ (III) halides. ${ }^{3,6-8,27,28}$ In comparison, the emission from $3 \mathrm{D}$ $\mathrm{CH}_{3} \mathrm{NH}_{3} \mathrm{SnI}_{3}$ results from free-excitonic states, and the PL band is characterized by a small Stokes shift, a narrow full width at half-maximum (FWHM), and a fast radiative lifetime. ${ }^{12,29}$

Both organic and inorganic constituents determine the resulting crystal structure. Thus, organic cations such as formamidinium $\left[\mathrm{CH}\left(\mathrm{NH}_{2}\right)^{+}, \mathrm{FA}\right]$ facilitate the formation of the $3 \mathrm{D}$ perovskite network of $\mathrm{FASnI}_{3} .{ }^{12}$ However, the use of large cations, such as phenethylammonium $\left[\mathrm{C}_{6} \mathrm{H}_{5}\left(\mathrm{CH}_{2}\right)_{2} \mathrm{NH}_{3}{ }^{+}\right]$, typically results in a layered structure. ${ }^{22}$ A cation that is only slightly larger than FA - guanidinium forms a layered $\mathrm{G}_{2} \mathrm{SnI}_{4}$ perovskite crystal structure with corrugated $\mathrm{Sn}-\mathrm{I}$ layers. ${ }^{30}$ Guanidinium is a highly symmetric molecule $\left(D_{3 h}\right)$ and a potential contributor of six hydrogen bonds. The $\mathrm{G}$ cation due to its larger-than-FA ionic radius destabilizes the 3D perovskite network of corner-shared Sn-X octahedra. ${ }^{31}$ Instead, $\mathrm{GSnI}_{3}$ forms a 3D network composed of $\mathrm{Sn}-\mathrm{I}$ octahedra with mixed connectivity: corner- and facesharing. ${ }^{1}$ The appealing attributes of the $\mathrm{G}$ cation are its high thermodynamic stability, strong hydrogen bonding capabilities, and high basicity with $\mathrm{p} K_{\mathrm{a}}=13.6$ due to resonance stabilization by $6-8 \mathrm{kcal} / \mathrm{mol} .{ }^{32,33}$ In a $\mathrm{G}-\mathrm{Sn}-\mathrm{Cl}$ system, there are two known compounds: $1 \mathrm{D} \mathrm{G}_{2} \mathrm{SnCl}_{4}$ and the $3 \mathrm{D}$ perovskite-like $\mathrm{GSnCl}_{3}{ }^{34,35}$ Unlike $\mathrm{G}_{2} \mathrm{SnI}_{4}$ where the building blocks are $\mathrm{Sn}-\mathrm{I}$ octahedra, $\mathrm{G}_{2} \mathrm{SnCl}_{4}$ has square pyramidal $\mathrm{Sn}$ (II) surrounded by $\mathrm{Cl}$ ions. So far, no compounds have been reported in the $\mathrm{G}-\mathrm{Sn}-$ Br system.

Herein, we investigated the $\mathrm{G}-\mathrm{Sn}-\mathrm{Br}$ and mixed-cation $\mathrm{Cs}-$ $\mathrm{G}-\mathrm{Sn}-\mathrm{X}(\mathrm{X}=\mathrm{Br}, \mathrm{I})$ systems wherein the effect of the additional smaller cation on the obtained structure can be probed. In our study, we did not succeed in obtaining quaternary mixed CsG-Sn(II) iodides and instead observed known ternary $\mathrm{G}_{2} \mathrm{SnI}_{4}{ }^{1,30}$ and $\mathrm{CsSnI}_{3}$ phases. ${ }^{36}$ Therefore, the focus has been on the bromide systems. We have synthesized $\mathrm{G}_{2} \mathrm{SnBr}_{4}$ (I) (Figure 1a) and compared it to $\mathrm{CsSnBr}_{3}$, and subsequently explored mixed Cs/G phases. $\mathrm{G}_{2} \mathrm{SnBr}_{4}$ is a $1 \mathrm{D}$ luminescent 
compound with broadband PL and a PLQY of $2 \%$ at RT. It is thermally stable up to $300{ }^{\circ} \mathrm{C}$. Two layered perovskite compounds, $\mathrm{CsGSnBr}_{4}$ (II) and $\mathrm{Cs}_{2} \mathrm{GSn}_{2} \mathrm{Br}_{7}$ (III), were obtained and characterized in terms of their crystal structure, electronic structure, and optical properties. They reveal significant quantum confinement and that the planar shape of the $G$ cation induces significant structural and electronic anisotropy. We then compare these structural effects to those in homologous lead-based compounds.

\section{METHODS}

Chemicals, reagents and synthetic procedures. Guanidinium carbonate $\left(\mathrm{G}_{2} \mathrm{CO}_{3},>99 \%\right)$, hydrobromic acid $(\mathrm{HBr}, 48 \%$ water solution), and $\mathrm{Sn}$ powder $(99.8 \%, \sim 325$ mesh) were purchased from Acros. Cesium bromide (CsBr, 99\%) and hydroiodic acid (HI, 57\% water solution stabilized with $1.5 \%$ hypophosphorous acid, $\mathrm{H}_{3} \mathrm{PO}_{2}$ ) were obtained from ABCR. Tin(II) bromide $\left(\mathrm{SnBr}_{2}, 99.2 \%\right)$ was obtained from Alfa Aesar. All chemicals were used as received without further purification.

All syntheses and further manipulations with the products were performed under inert conditions (argon or nitrogen atmosphere) using the Schlenk technique. Temperatures of the syntheses, stated below, correspond to the temperatures of the glycerol bath used as a source of heat. The syntheses were conducted in 10-20 ml Schlenk vessels equipped with a stirring bar.

$\mathrm{G}_{2} \mathrm{SnBr}_{4}(\mathrm{I})$ was crystallized from $\mathrm{HBr}$. Briefly, $0.250 \mathrm{~g}(2.1 \mathrm{mmol})$ of Sn powder was dissolved in $3 \mathrm{~mL}$ of $\mathrm{HBr}$ (degassed under stirring in $\mathrm{Ar}$ atmosphere for $\sim 20 \mathrm{~min}$ beforehand); this mixture was stirred for 10 min at RT and then heated in the glycerol bath at $85-90^{\circ} \mathrm{C}$. When all of the $\mathrm{Sn}$ was dissolved, $0.378 \mathrm{~g}(2.1 \mathrm{mmol})$ of $\mathrm{G}_{2} \mathrm{CO}_{3}$ was slowly added. Strong evolution of gas was observed $\left(\mathrm{CO}_{2}\right)$. The reaction mixture was then stirred for an additional $5 \mathrm{~min}$ resulting in a clear colorless solution, whereupon the stirring and the heating were discontinued. Colorless transparent needles crystallized upon cooling and were separated by vacuum filtration under Ar flow. The product was dried under vacuum at $65-70{ }^{\circ} \mathrm{C}$ for $6 \mathrm{~h}$. Yield: $41 \%$ (with regard to the initial $[\mathrm{Sn}])$.

$\mathrm{CsSnBr}_{3}$ was synthesized from stoichiometric quantities of $\mathrm{Sn}$ and $\mathrm{CsBr}$ precursors in $\mathrm{HBr}$. Briefly, $0.180 \mathrm{~g}(1.5 \mathrm{mmol})$ of $\mathrm{Sn}$ was dissolved in $3 \mathrm{~mL}$ of $\mathrm{HBr}$ as described above. Next, $0.320 \mathrm{~g}(1.5 \mathrm{mmol})$ of $\mathrm{CsBr}$ was added, and a black precipitate formed immediately. A mixture was stirred for an additional $5 \mathrm{~min}$ at $105{ }^{\circ} \mathrm{C}$. Further manipulations with the product were identical to those with $\mathrm{G}_{2} \mathrm{SnBr}_{4}$.

For the preparation of $\mathrm{Cs}_{2} \mathrm{GSn}_{2} \mathrm{Br}_{7}$ (III), $0.107 \mathrm{~g}(0.9 \mathrm{mmol})$ of $\mathrm{Sn}$ powder was dissolved in $3 \mathrm{~mL}$ of $\mathrm{HBr}$, stirred for $10 \mathrm{~min}$ at RT, and then heated to $85-90{ }^{\circ} \mathrm{C}$. When all of the $\mathrm{Sn}$ was dissolved, $0.486 \mathrm{~g}(2.7$ $\mathrm{mmol})$ of $\mathrm{G}_{2} \mathrm{CO}_{3}$ and $0.1915 \mathrm{~g}(0.9 \mathrm{mmol})$ of $\mathrm{CsBr}$ were slowly added. Strong evolution of gas $\left(\mathrm{CO}_{2}\right)$ was observed, and a black precipitate formed. The reaction mixture was stirred and kept at $85-90^{\circ} \mathrm{C}$ for $\sim 5$ min until a slightly yellowish solution was obtained. Next, the stirring and heating were discontinued, and the mixture was cooled down under a stream of cold tap water. Initially, some black precipitate of $\mathrm{CsSnBr}_{3}$ crystallized out (Figure S1). In a few minutes, red crystals started appearing, and the black powder redissolved. The mixture was left to further crystallize for 1 week. Finally, the red product was separated by vacuum filtration under an inert atmosphere and dried under vacuum at $65-70{ }^{\circ} \mathrm{C}$ for $6 \mathrm{~h}$.

$\mathrm{Cs}_{8} \mathrm{Sn}_{6} \mathrm{Br}_{13} \mathrm{I}_{7}$ was crystallized from a solution of hot $\mathrm{HI}$ and $\mathrm{HBr}$ acids under $\mathrm{N}_{2}$. $\mathrm{CsBr}(0.500 \mathrm{~g}, 2.350 \mathrm{mmol})$ was first dissolved in $\mathrm{HBr}(4.0$ $\mathrm{mL})$ and $\mathrm{HI}(1.0 \mathrm{~mL})$ solution in a $10 \mathrm{~mL}$ Schlenk reaction tube and sparged with $\mathrm{N}_{2}$ while stirring at RT for $30 \mathrm{~min}$. $\mathrm{SnBr}_{2}(0.111 \mathrm{~g}, 0.399$ $\mathrm{mmol}$ ) was then added, and a black precipitate formed. This mixture was then heated with a glycerol bath until an orange solution was obtained $\left(110^{\circ} \mathrm{C}\right)$. The stirring and heating were discontinued, and the solution was cooled to RT. Within $1 \mathrm{~h}$, orange needles crystallized out. The solution was left to further crystallize overnight. The product was separated by vacuum filtration under $\mathrm{N}_{2}$ and dried overnight under vacuum $\left(70-80^{\circ} \mathrm{C}\right)$. A yield of $50.8 \%$ was estimated relative to initial [Sn].

Characterization. Powder X-ray diffraction (XRD) patterns were collected in transmission mode (Debye-Scherrer Geometry) with a STADI P diffractometer (STOE\& $\mathrm{Cie} \mathrm{GmbH}$ ) equipped with a curved Ge $(111)$ monochromator $(\mathrm{CuK} \alpha 1=1.54056 \AA)$ and a silicon strip MYTHEN 1K Detector (Fa. DECTRIS). For the measurement, a ground powder was placed between adhesive tape (for $\mathrm{CsGSnBr}_{4}$ and $\mathrm{Cs}_{2} \mathrm{GSn}_{2} \mathrm{Br}_{7}$ ) or sealed in a $0.3 \mathrm{~mm}$ glass capillary (for $\mathrm{G}_{2} \mathrm{SnBr}_{4}$ and $\mathrm{CsSnBr}$ ). Single-crystal XRD measurements were conducted on a Bruker Smart Platform diffractometer equipped with an Apex I CCD detector and a molybdenum $(\mathrm{MoK} \alpha=0.71073 \AA)$ sealed tube as an $\mathrm{X}$ ray source. Crystals were tip-mounted on a micromount with paraffin oil. The data was processed with the APEX3 software package, ${ }^{37}$ and the structure solution and refinement were performed with SHELXS ${ }^{38}$ and SHELXL, ${ }^{39}$ respectively, which are embedded in Olex2. ${ }^{40}$ The crystal structures were solved with direct methods, light elements (C, $\mathrm{N}$ ) were located in the difference Fourier map, and hydrogen atoms were placed at calculated positions. The crystallographic data for the reported tin halide compounds were deposited at the Cambridge Crystallographic Data Centre (CCDC) under the codes 1854819 $\left(\mathrm{G}_{2} \mathrm{SnBr}_{4}\right), 1854833\left(\mathrm{Cs}_{2} \mathrm{GSn}_{2} \mathrm{Br}_{7}\right)$, and $1854838\left(\mathrm{CsGSnBr}_{4}\right)$, as well as at the Inorganic Crystal Structure Database (ICSD), that is, card number 434800 for $\mathrm{Cs}_{8} \mathrm{Sn}_{6} \mathrm{Br}_{13} \mathrm{I}_{7}$. UV-Vis diffuse reflectance spectra of the microcrystalline powders were collected using a Jasco V670 spectrophotometer equipped with a deuterium $\left(D_{2}\right)$ lamp (190-350 $\mathrm{nm})$ for use in UV and a halogen lamp $(330-2700 \mathrm{~nm})$ for use in UV/ NIR, and an integrating sphere detector (ILN-725) with a working wavelength range of $220-2200 \mathrm{~nm}$. The diffuse reflectance data were transformed with the Kubelka-Munk model into the absorption/ scattering ratio spectrum. Photoluminescence spectra were measured with a CCD fiber spectrometer (LR1, Aseq Instruments) with a $355 \mathrm{~nm}$ excitation source (frequency-tripled, picosecond Nd:YAG laser, Duetto from Time-Bandwidth). PL emission from the samples was passed through a long-pass optical filter with an edge at $400 \mathrm{~nm}$ to reject the excitation laser line. PL spectra were corrected to the spectral sensitivity of the detection system. For temperature-dependent PL measurements, a sample of $\mathrm{CsSnBr}_{3}$ was placed atop of a four-stage Peltier cooling/ heating element in an evacuated chamber with a quartz window. The sample temperature was adjusted and stabilized with an accuracy of $0.25{ }^{\circ} \mathrm{C}$ by a homemade electronic scheme based on an Arduino microcontroller and thermocouple sensor. The current through the Peltier system was reversible, thus the setup provided a wide working temperature range of -40 to $120^{\circ} \mathrm{C}$. This is an open-source project by the authors, deposited and described in details at https://www. researchgate.net/project/High-power-thermoelectric-cooler-TECcontroller-with-4-stage-Peltier-refrigerator-heater. Time-resolved photoluminescence (TR-PL) measurements were performed using a timecorrelated single-photon counting (TCSPC) setup, equipped with an SPC-130-EM counting module (Becker \& Hickl GmbH) and an IDQID-100-20-ULN avalanche photodiode (Quantique) for recording the decay traces. The average radiative lifetimes were determined as $\tau_{\text {avg }}=\frac{\sum_{i=1}^{2} \tau_{i}^{2} \cdot A_{i}}{\sum_{i=1}^{2} \tau_{i} \cdot A_{i}}$, where $A_{i}$ and $\tau_{i}$ are the corresponding amplitudes and exponential decay parameters in the biexponential analysis. For measurements of PL and PLE spectra at low temperature (77 K), the sample was encapsulated in a quartz tube filled with Ar gas and placed in a homemade cryostat. Low-temperature (77 K) and RT absolute PLQY values were measured with excitation at $340 \mathrm{~nm}$ using Quantaurus-QY spectrometer from Hamamatsu. The sample was encapsulated in a quartz tube filled with Ar gas. PL measurements at lower temperatures (in the case of $\mathrm{Cs}_{2} \mathrm{GSn}_{2} \mathrm{Br}_{7}$ ), down to $5 \mathrm{~K}$, were conducted in a helium cryostat, and PL spectroscopy was performed by exciting the sample with a frequency-doubled Ti:Sapphire mode-locked laser delivering pulses of $\sim 150 \mathrm{fs}$ duration at $400 \mathrm{~nm}$ and a repetition rate of $80 \mathrm{MHz}$. The time-integrated PL was analyzed using a CCD-coupled grating spectrometer, whereas TR-PL traces were recorded with a streak camera. Thermal analysis [thermogravimetry (TG) and differential scanning calorimetry (DSC)] was performed using a Netzsch simultaneous thermal analyzer (STA 449 F5 Jupiter). A powdered 

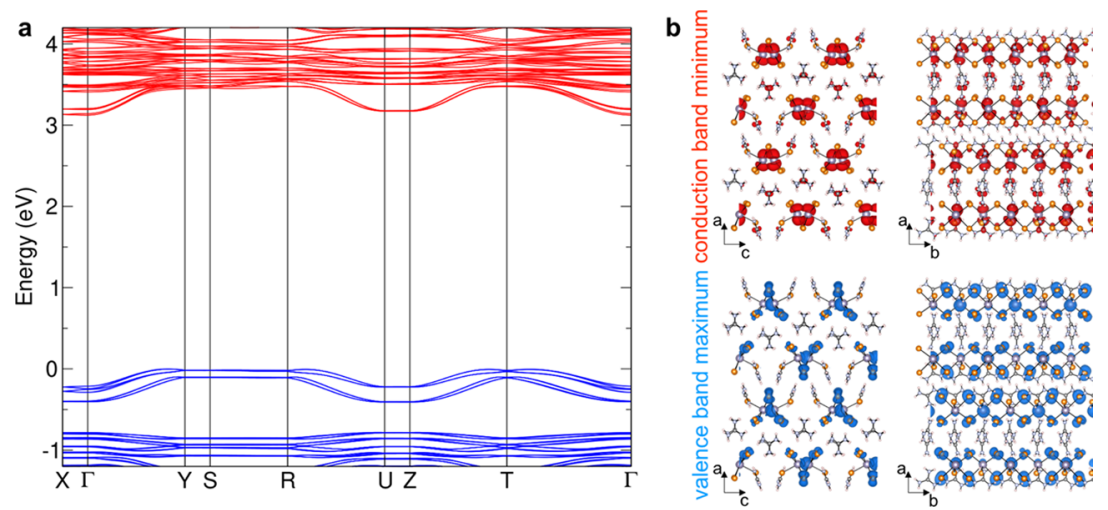

Figure 2. (a) Electronic band diagram of $\mathrm{G}_{2} \mathrm{SnBr}_{4}(\mathrm{I})$ computed by DFT. No dispersion can be observed except in the direction of the 1D chains [010] $\left(\Gamma \rightarrow \mathrm{Y}, \mathrm{R} \rightarrow \mathrm{U}\right.$, and $\mathrm{Z} \rightarrow \mathrm{T}$ paths). The space group $P n a 2_{1}$ is a polar space group. Therefore, a Rashba splitting of the band edge states is predicted both in the conduction and valence bands away from the $\mathrm{Y}, \mathrm{R}$, and $\mathrm{T}$ critical points of the Brillouin zone. (b) Representation of the electronic densities of the conduction (red) and valence (blue) edge states.

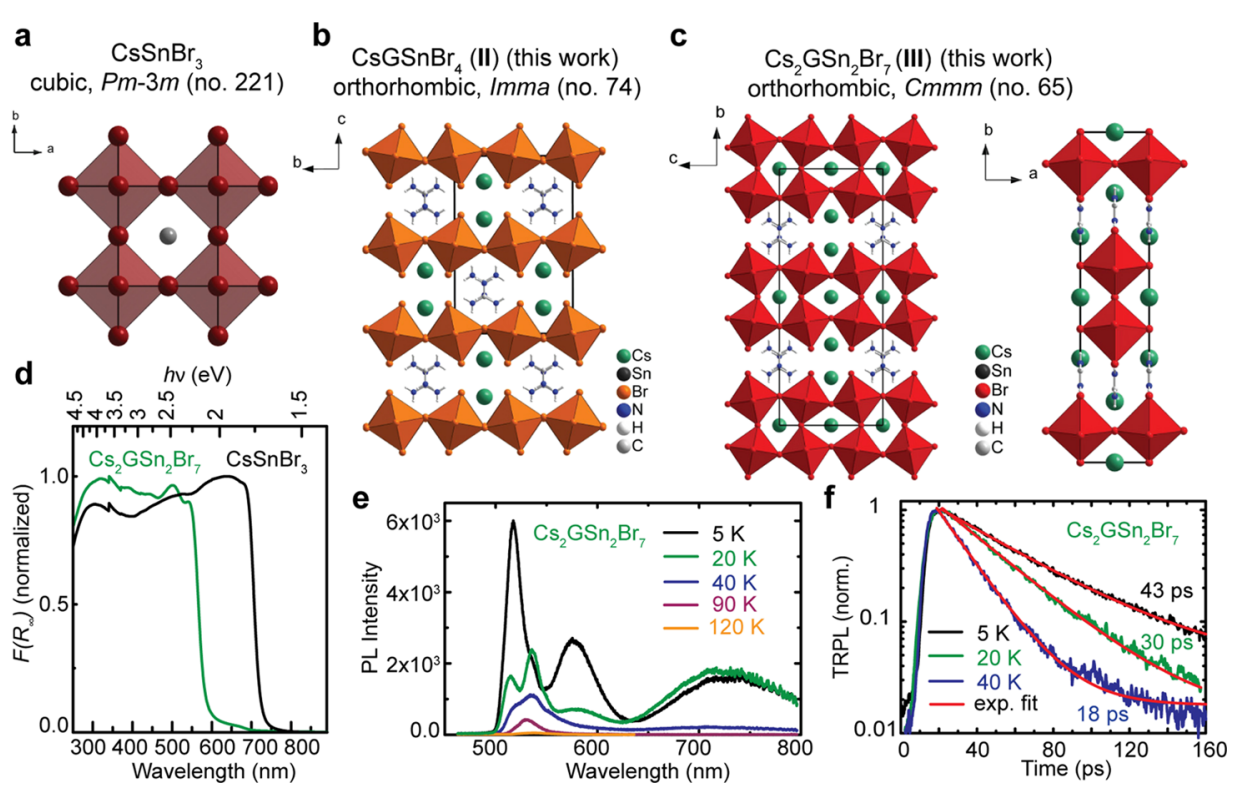

Figure 3. (a) Crystal structure of cubic $3 \mathrm{D}$-perovskite $\mathrm{CsSnBr}_{3}$. (b, c) Crystal structure of $2 \mathrm{D}$ perovskites: $\mathrm{CsGSnBr}_{4}\left(\mathrm{II}_{)}\right.$and $\mathrm{Cs}_{2} \mathrm{GSn}_{2} \mathrm{Br}_{7}(\mathrm{III})$. (d) Kubelka-Munk function of CsSnBr$r_{3}$ and III at RT. (e) Selected low-temperature PL spectra of III. (f) Selected low-temperature time-resolved PL spectra of III.

sample of $\mathrm{G}_{2} \mathrm{SnBr}_{4}(21.9 \mathrm{mg})$ was placed in an alumina crucible (without a lid) and heated under Ar gas flow $\left(50 \mathrm{~mL} / \mathrm{min}\right.$ ) to $850{ }^{\circ} \mathrm{C}$ $\left(10{ }^{\circ} \mathrm{C} \min ^{-1}\right)$. Scanning electron microscopy (SEM) was carried out on a Quanta 200F microscope (Thermo Fisher Scientific) operated at an acceleration voltage of $20 \mathrm{kV}$.

Energy-dispersive X-ray spectroscopy (EDXS) was performed with an Octane SDD detector (EDAX, Ametec) attached to the microscope column. For spectra recording and quantification (ZAF correction), the software Gemini (EDAX) was used.

Computational details. First-principles calculations were performed with experimental crystal structures using density functional theory (DFT) as implemented in the SIESTA package. ${ }^{41,42}$ Calculations have been carried out on experimental structures with the GGA functional in the PBE form. ${ }^{43}$ Core electrons were described with Troullier-Martins pseudopotentials, ${ }^{44}$ whereas valence wave functions were developed over a double- $\zeta$ polarized basis set of finiterange numerical pseudoatomic orbitals. ${ }^{45}$ Spin-orbit coupling was taken into account through the on-site approximation as proposed by Fernández-Seivane et al. ${ }^{46}$ In all cases, an energy cutoff of 150 Ry for real-space mesh size was used.

\section{RESULTS AND DISCUSSION}

All presented compounds were crystallized from hydrobromic acid ( $\mathrm{HBr}, 48 \%$ water solution) under an argon atmosphere using $\mathrm{Sn}$ powder, $\mathrm{CsBr}$, and $\mathrm{G}_{2} \mathrm{CO}_{3}$ as precursors. $\mathrm{G}_{2} \mathrm{SnBr}_{4}(\mathrm{I})$, obtained from stoichiometric quantities of $G$ and $S n(I I)$, crystallizes as colorless transparent needles. Compound I was then characterized by single-crystal XRD (Figure 1a,b, Figure S2, and Tables S1-S4) and found to crystallize in the orthorhombic crystal system, space group $P n a 2_{1}$. This structure consists of corrugated chains oriented along [010] (i.e., extended in the $b$ direction), comprising corner-sharing square pyramids, $\left[\mathrm{SnBr}_{5}\right]^{2-}$. The formation of such pyramids emphasizes the stereoactivity of the lone pair of $\mathrm{Sn}$ (II). The G cations are situated in the space between the chains and connect them via hydrogen-halogen bonds into a $3 \mathrm{D}$ supramolecular structure (Table S2). Two non-equivalent pyramids can be identified, which connect in an alternating manner. In both kinds of pyramids, $\mathrm{Sn}$ atoms are displaced out of the basal planes (by 0.23 and $0.24 \AA$, for $\mathrm{Br} 1 \mathrm{Br} 2 \mathrm{Br} 5 \mathrm{Br} 4$ and $\mathrm{Br} 2 \mathrm{Br} 5 \mathrm{Br} 8 \mathrm{Br} 7$ planes, 
respectively, Figure $1 \mathrm{~b}$ ). The $\mathrm{Sn}-\mathrm{Br}$ bond lengths are in the range of $2.724(2)-3.117 \AA$, which is comparable to the distances found in $\left(\mathrm{NH}_{4}\right) \mathrm{SnBr}_{3} \times \mathrm{H}_{2} \mathrm{O}$ (2.623-3.047 $\AA$ ), where $\mathrm{Sn}$ (II) has the same square-pyramidal coordination. ${ }^{47}$ The shortest $\mathrm{Sn}-\mathrm{Br}$ bond is with the $\mathrm{Br}$ ion at the apex of the pyramid. $\mathrm{G}_{2} \mathrm{SnBr}_{4}$ (I) has a similar crystal structure to $\mathrm{G}_{2} \mathrm{PbBr}_{4}$, which contains an alternating orientation of $\left[\mathrm{PbBr}_{5}\right]^{2-}$ square pyramids in $1 \mathrm{D}$ chains. ${ }^{48}$ The $1 \mathrm{D}$ character is confirmed by inspection of the DFT electronic structure (Figure 2). Indeed, the band diagram (Figure 2a) exhibits an indirect band gap of $3.12 \mathrm{eV}$, and no dispersion of the edge state bands is observed except when following a path corresponding to the [010] crystal direction. Furthermore, the computed electronic edge state densities exhibit sizeable overlaps but only along the $b$ crystallographic direction (Figure 2b), thus confirming the $1 \mathrm{D}$ character of the density of states close to the band gap. It is also worth noticing that Rashba splitting of the band edge states is observed both in the conduction and valence bands away from the $\mathrm{Y}, \mathrm{R}$, and $\mathrm{T}$ critical points of the Brillouin zone as a result of the polar space group $P n a 2_{1}$ assigned to (I). Sn-I square pyramidal units were also observed when using larger cations, such as $\left[\mathrm{C}_{3} \mathrm{H}_{7} \mathrm{~N}\left(\mathrm{C}_{2} \mathrm{H}_{4}\right)_{3} \mathrm{NC}_{3} \mathrm{H}_{7}\right]^{2+} .{ }^{19} \mathrm{G}_{2} \mathrm{SnBr}_{4}(\mathrm{I})$ is thermally stable up to at least $300{ }^{\circ} \mathrm{C}$ (see TGA/DSC analysis in Figure S3). Two endothermic processes without mass loss occur before the decomposition at around 146 and $190{ }^{\circ} \mathrm{C}$ and indicate melting and/or other structural transitions.

Studies on a ternary $3 \mathrm{D}$ phase - the black $\mathrm{CsSnBr}_{3}-$ date back to as early as the 1970 s. $\mathrm{CsSnBr}_{3}$ crystallizes in a cubic perovskite crystal structure (space group $P m-3 m$, Figure $3 a$ ) and melts congruently at $450{ }^{\circ} \mathrm{C} .^{49-51} \mathrm{~A}$ phase transition to a tetragonally distorted lattice appears upon cooling to below 19 ${ }^{\circ} \mathrm{C} .{ }^{51}$ The yellow $\mathrm{CsSnI}_{3}$ crystallizes in the orthorhombic crystal system. $\mathrm{CsSnI}_{3}$ is a $1 \mathrm{D}$ compound composed of edge-sharing $\left[\mathrm{SnI}_{6}\right]^{-1}$ octahedra $^{52}$ and converts into a cubic $3 \mathrm{D}$ phase only at $152{ }^{\circ} \mathrm{C} .{ }^{51}$ Similarly, $\mathrm{CsPbI}_{3}$ is known to crystallize in a $3 \mathrm{D}$ lattice (cubic, space group $\mathrm{Pm}-3 \mathrm{~m}$ ) at higher temperatures and converts into a $1 \mathrm{D}$ phase, analogous to $1 \mathrm{D}-\mathrm{CsSnI}_{3}$, within the 329-290 ${ }^{\circ} \mathrm{C}$ temperature range. ${ }^{.3}$

We were then interested to see the effect of $\mathrm{Br}-\mathrm{I}$ mixing in the $\mathrm{Cs}-\mathrm{Sn}-\mathrm{X}$ system. Interestingly, the addition of iodide with $[\mathrm{I}] /$ $[\mathrm{Sn}]=19 / 1$ (in concentrated $\mathrm{HBr}$ ) leads to the precipitation of $\mathrm{Cs}_{8} \mathrm{Sn}_{6} \mathrm{Br}_{13} \mathrm{I}_{7}$ in the form of orange needles. It crystallizes in the orthorhombic crystal system, space group $\mathrm{Cmcm}$ (Tables S5S7) and consists of layers of corner- (through $\mu_{2}-\mathrm{Br}$ ) and edgesharing (through $\mu_{3}$-I ions) distorted $\left[\mathrm{SnBr}_{4} \mathrm{I}_{2}\right]^{-5 / 3}$ and $\left[\mathrm{SnBr}_{3} \mathrm{I}_{3}\right]^{-7 / 6}$ octahedra (Figure $\mathrm{S} 4 \mathrm{a}, \mathrm{b}$ ). Iodide has one full and two partially occupied positions that are shared with bromide ions. The $\mathrm{Cs}^{+}$cations are situated in between, as well as within, $\mathrm{Sn}$ (II) halide layers. There are two types of crystallographic surroundings for the $\mathrm{Sn}(\mathrm{II})$ ions; one characterized by the presense of a very weak $\mathrm{Sn}-\mathrm{I}$ bond of $3.723 \AA$, in $\left[\mathrm{SnBr}_{3} \mathrm{I}_{3}\right]^{-7 / 6}$ octahedra (see Sn1 atom in Figure S4b). The Sn2-I1 distances within $\left[\mathrm{SnBr}_{4} \mathrm{I}_{2}\right]^{-5 / 3}$ are $3.454 \AA$, which is in the range of $d(\mathrm{Sn}-$ I) in $\mathrm{CsSnI}_{3}, 2.942-3.470 \AA \AA^{52}$ Based on powder XRD analysis, $\mathrm{Cs}_{8} \mathrm{Sn}_{6} \mathrm{Br}_{13} \mathrm{I}_{7}$ was obtained as a pure phase (Figure S4c) with a homogeneous composition that was estimated with EDX (Figure $\mathrm{S} 5 \mathrm{a}-\mathrm{c}$ ). The same structural motif was found in $\mathrm{Cs}_{2.38} \mathrm{Rb}_{1.62} \mathrm{Sn}_{3} \mathrm{Cl}_{8} \mathrm{I}_{2}$, recently reported by $\mathrm{Li}$ et al., ${ }^{54}$ obtained by solid-state reaction. The optical band edge of $\mathrm{Cs}_{8} \mathrm{Sn}_{6} \mathrm{Br}_{13} \mathrm{I}_{7}$ lies at $2.23 \mathrm{eV}$ (Figure S6a,b), which is $0.58 \mathrm{eV}$ smaller than the optical band gap of $\mathrm{Cs}_{2.38} \mathrm{Rb}_{1.62} \mathrm{Sn}_{3} \mathrm{Cl}_{8} \mathrm{I}_{2}$. ${ }^{54}$
By comparing the experimental powder XRD patterns with those simulated from single-crystal XRD data obtained herein (except for $\mathrm{CsSnBr}_{3}$, where ICSD card 4071 was used), I and $\mathrm{CsSnBr}{ }_{3}$ were determined to be phase-pure (Figures S7 and S8). $\mathrm{CsSnBr}$ also appears to contain amorphous $\mathrm{CsSnBr}_{3}$ (Figure S8), which can explain the partially resolved component at 650$700 \mathrm{~nm}$ in the PL spectrum (Figure 1d). We then obtained two mixed guanidinium-cesium tin bromides: $\mathrm{CsGSnBr}_{4}$ (II, orange-colored) and $\mathrm{Cs}_{2} \mathrm{GSn}_{2} \mathrm{Br}_{7}$ (III, red-colored), as a mixture of crystals. Both compounds are layered perovskites (Figure 3b,c). The formation of these phases was found to be in strong competition with the crystallization of compounds I and $\mathrm{CsSnBr}_{3} \cdot \mathrm{Cs}_{2} \mathrm{GSn}_{2} \mathrm{Br}_{7}$ (III) was obtained as the dominant phase, with $\mathrm{CsGSnBr}_{4}$ (II) as a major impurity (below $10 \%$, Figure S9) at a molar ratio of $\mathrm{Cs} / \mathrm{G} / \mathrm{Sn}=1 / 6 / 1$. Optical absorption analysis of the sample of $\mathrm{Cs}_{2} \mathrm{GSn}_{2} \mathrm{Br}_{7}$ by a Kubelka-Munk function points to a possible trace quantity of rather amorphous $\mathrm{CsSnBr}_{3}$, thus giving rise to a small shoulder in the $650-700 \mathrm{~nm}$ region (Figure 3d). Both II and III crystallize in the orthorhombic crystal system, namely in Imma (II) and Cmmm (III) space groups, respectively (Figure $3 b, c$ and Table S1). The crystal structures of II and III consist of $2 \mathrm{D}$ perovskite layers of cornersharing $\left[\mathrm{SnBr}_{6}\right]^{4-}$ octahedra that are separated by cesium and guanidinium cations. The derivation of these structures can be visualized by cutting the parental cubic $\mathrm{CsSnBr}_{3}$ perovskite lattice along the (100) crystallographic plane and adding the octahedral tilting (discussed later in detail). The importance of the mixed-cation design for obtaining $2 \mathrm{D}$ perovskites had been previously reported for the analogous $\mathrm{CsGPbBr}(\mathrm{I})_{4}$ and $\mathrm{Cs}_{2} \mathrm{GPb}_{2} \mathrm{Br}_{7}$ compounds. ${ }^{48}$ Compound II contains monolayers of corner-sharing octahedra (Figure $3 \mathrm{~b}$ ), whereas compound III features double layers, connected via corners (Figure $3 \mathrm{c}$ ). To the best of our knowledge, this is the first tin bromide featuring multilayers. The perovskite slabs are mutually shifted in-plane by a vector $a / 2$ ( $a$ being an ideal cubic cell vector, Figure $3 c$ ). $\mathrm{Cs}^{+}$ and G cations in II and III are both situated in the interlayer space and alternate with each other in a periodic manner. In $\mathrm{Cs}_{2} \mathrm{GSn}_{2} \mathrm{Br}_{7}$ (III), cesium cations also fill the voids within the perovskite layers. $\mathrm{G}$ forms hydrogen bonds with the bromide ions from the perovskite layers (Tables S8 and S9). G cations are closely packed with intermolecular $d(\mathrm{C} \cdots \mathrm{N})$ distance of $\sim 3 \AA$. Due to the difference in ionic radii of the $\mathrm{Cs}^{+}$and $\mathrm{G}$ cations and the planar shape of the latter, $\mathrm{Sn}-\mathrm{Br}$ octahedra are tilted in an alternating manner along the crystallographic axes $b$ and $c$ for II (Figure 3b) and III (Figure 3c, left), respectively. This generates smaller cavities for $\mathrm{Cs}^{+}$and large voids for $\mathrm{G}$ cations. However, in the in-plane direction (for instance, along the crystallographic axis $a$ for III, Figure 3c, right) the planar shape of the G cation and small atomic radius of $\mathrm{Cs}^{+}$lead to the absence of steric strain with almost perfectly collinear $\mathrm{Sn}$ and $\mathrm{Br}$ atoms and subsequently longer $\mathrm{Sn}-\mathrm{Sn}$ distances (6.011 and $5.965 \AA$ for II and III, respectively). This might contribute to an observed disorder in atomic positions of bromide along this direction. In $\mathrm{CsGSnBr}_{4}(\mathrm{II}), d(\mathrm{Sn}-\mathrm{Br})=2.909(2)-3.006(1) \AA$, which is comparable to $\mathrm{Sn}-\mathrm{Br}$ distances in a $\mathrm{CsSnBr}_{3}$ cubic phase $[d(\mathrm{Sn}-\mathrm{Br})=2.898 \AA] .{ }^{49} \mathrm{Sn}-\mathrm{Br}-\mathrm{Sn}$ angles are in the range of $155.9(5)-180.0^{\circ}$ (Figure S10). CsGSnBr ${ }_{4}$ and $\mathrm{CsGPbBr}_{4}$ both crystallize in the space group Imma and are isotypic. ${ }^{48}$ III is isotypic to $\mathrm{Cs}_{2} \mathrm{GPb}_{2} \mathrm{Br}_{7}$ and crystallizes in the space group $\mathrm{Cmmm} .{ }^{48}$ The average $\mathrm{Sn}-\mathrm{Br}$ distances for III are in the range of 2.915-2.987(1) Å (for additional crystallographic data for II and III, see Tables S10-S13).The interlayer $\mathrm{Br} \cdots \mathrm{Br}$ distances along the stacking direction ( $c$ and $b$ for II and III, respectively) 

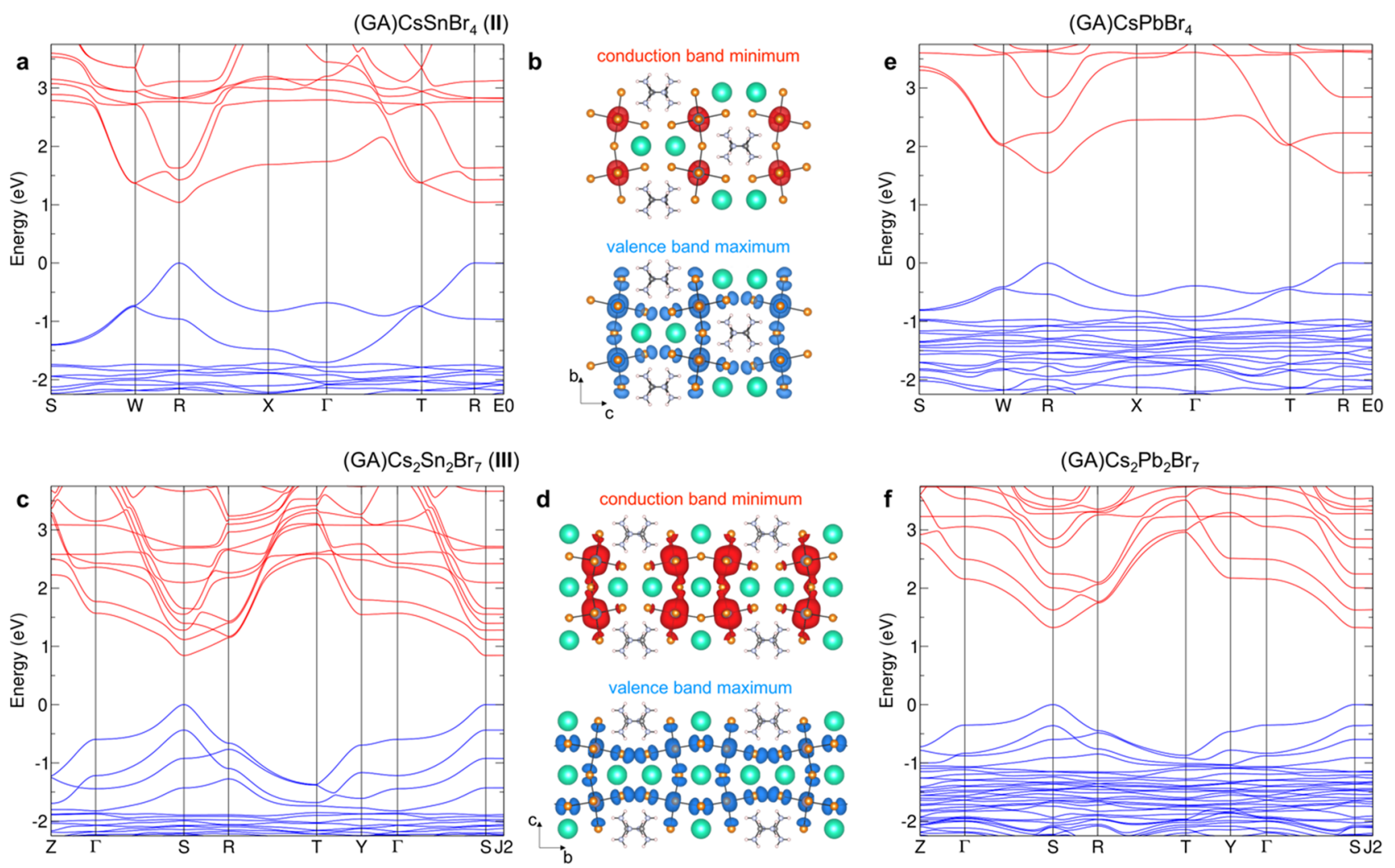

Figure 4. (a) Electronic band structure and (b) representation of the electronic densities of the conduction (red) and valence (blue) edge states (at the $\mathrm{R}$ point of the Imma Brillouin zone) of $\mathrm{CsGSnBr}_{4}$ (II). R $\rightarrow$ E0 corresponds to the stacking direction. (c) Electronic band structure and (d) representation of the electronic densities for $\mathrm{Cs}_{2} \mathrm{GSn}_{2} \mathrm{Br}_{7}$ (III). S $\rightarrow \mathrm{J} 2$ corresponds to the stacking direction. (e) Electronic band structures of $\mathrm{CsGPbr}_{4}$ and (f) $\mathrm{Cs}_{2} \mathrm{GPb}_{2} \mathrm{Br}_{7}$. Electron densities are computed at the $R$ point for II (b) and the $S$ point for III (d).

are rather short: $d(\mathrm{Br} \cdots \mathrm{Br})=4.161 \AA$ in $\mathrm{CsGPbBr}_{4}$ (II) and $d(\mathrm{Br} \cdots \mathrm{Br})=4.070 \AA$ in $\mathrm{Cs}_{2} \mathrm{GSn}_{2} \mathrm{Br}_{7}(\mathrm{III})$.

In $3 \mathrm{D}$ perovskites, the critical point of the Brillouin zone where a direct band gap is observed is either the $R$ point, ${ }^{55}$ for the cubic $P m-3 m$ phase, or the $Z$ point for the distorted tetragonal $\mathrm{P} 4 / \mathrm{mbm}$ phase (Figure S11). In both cases, the critical wave vectors have the point symmetries of their respective lattices $(m-3 m$ and $4 / \mathrm{mmm})$. Similar symmetry considerations lead to critical wave vectors located along the stacking directions at the $X(0,0,1)$ and $Y(0,1,0)$ high-symmetry points for II and III, respectively, in the Imma and Cmmm Brillouin zones (both with point groups $\mathrm{mmm}$ ). However, DFT simulations (Figure $4 \mathrm{a}, \mathrm{c}$ ) show that the electronic band gaps are predicted to be directly at the $R(0.5,0,0.5)$ and $S(0.5,0.5,0)$ points of the Brillouin zones of II and III, respectively. In both cases, the point symmetry of the critical wave vector is reduced from $m m m$ to $2 / m$. This can be related to the anisotropy of the out-of-plane octahedral tilts, which is directly induced by the shape of the $\mathrm{G}$ cations. The octahedral tilting is clearly apparent only in the $(b, c)$ crystallographic planes (Figure $3 b, c)$. The difference between II and III lies in the fact that the $(b, c)$ plane contains the stacking axis along $c$ for II and along $b$ for III. Furthermore, due to lattice distortions, the periodicity of the electronic density is doubled along $b(c)$ for II (III), in contrast to the $a$ direction. In turn, the valence band maxima and the conduction band minima show different hybridizations along all three directions (Figure 4b,d and Figure S12) as well as different band dispersions (Figure 4a,c). Both compounds II and III exhibit flat dispersions along the stacking axis despite the short $\mathrm{Br}-\mathrm{Br}$ distances, a characteristic feature of $2 \mathrm{D}$ systems.
Analogous to $\mathrm{CsSnBr}_{3}$ (Figure S11) and contrary to I (Figure 2), the band gap remains direct in both II and III (Figure 4a,c) with a systematic decrease of the band gap values with the decrease of dimensionality and thickness of perovskite layers. These variations in DFT band gap energies (Table S14) are related to the equivalent quantum well thickness $(n=1,2$, or $\infty$ ), which is roughly doubled when going from $\mathrm{CsGSnBr}_{4}$ (II) to $\mathrm{Cs}_{2} \mathrm{GSn}_{2} \mathrm{Br}_{7}$ (III) as a result of quantum confinement.

To experimentally probe the energy band gaps in these hybrid tin bromide compounds, an optical absorption analysis by means of a Kubelka-Munk function and PL measurements were performed (Figures 1c,d and 3d,e). The Kubelka-Munk absorption representation was derived from the diffuse reflectance spectra of powdered samples and was estimated as $F\left(R_{\infty}\right)=\alpha / S=\left(1-R_{\infty}\right)^{2} / 2 R_{\infty}\left[F\left(R_{\infty}\right)\right.$ is the Kubelka-Munk unit, $\alpha$ is the absorption coefficient, $S$ is the scattering coefficient, and $R_{\infty}$ is the reflectance of an infinitely thick layer]. Here, we neglected the influence of excitonic effects on the absorption, because the excitonic band cannot be consistently resolved for all compounds and thus correctly deconvoluted from the band gap absorption edge. Hence, the band gap can be slightly underestimated. The optical band gap energies for I, III, and $\mathrm{CsSnBr}_{3}$ were determined by plotting $\left[F\left(R_{\infty}\right) \cdot h \nu\right]^{r}$ versus $(h \nu)$ ( $h \nu$ is the incident photon energy, $r=2$ for a direct band gap semiconductor, and $r=1 / 2$ for an indirect band gap semiconductor; Figure S13a,b). The highest absorption edge energy (ca. $3.11 \mathrm{eV}$ ) was found for $\mathrm{G}_{2} \mathrm{SnBr}_{4}$ (I) (Figure 1c), which is in agreement with its lowest electronic dimensionality (1D). The $3 \mathrm{D}$ cubic $\mathrm{CsSnBr}_{3}$ has the smallest band gap energy $\left(1.74 \mathrm{eV}\right.$, in agreement with the literature $\left.{ }^{56}\right)$, whereas $2 \mathrm{D}$ 
$\mathrm{Cs}_{2} \mathrm{GSn}_{2} \mathrm{Br}_{7}$ (III) has an intermediate band gap value of $2.16 \mathrm{eV}$ (Figure $3 \mathrm{~d}$ ). Compound II could not be obtained in the phasepure form needed for diffuse reflectance (only individual small crystallites could be selected for single-crystal XRD analysis). However, the visual appearance of II pointed towards an expected higher band gap in comparison to III (orange vs red). Despite the well-known underestimation of band gaps, such a decrease is predicted from DFT calculations (Figure 4 and Table S14) with $1.04 \mathrm{eV}$ for II and $0.84 \mathrm{eV}$ for III. $\mathrm{Cs}_{2} \mathrm{GPb}_{2} \mathrm{Br}_{7}$ has a larger optical experimental band gap than III, by $0.44 \mathrm{eV}(2.60$ $\mathrm{eV}$ vs $2.16 \mathrm{eV}) .{ }^{48} \mathrm{~A}$ similar scenario was observed for the pair of $\left(\mathrm{C}_{6} \mathrm{H}_{9} \mathrm{C}_{2} \mathrm{H}_{4} \mathrm{NH}_{3}\right)_{2} \mathrm{SnBr}_{4}$ (2.5 eV optical band gap) and its lead analogue $(2.9 \mathrm{eV}) .^{57}$ This might be a result of the difference in the $E_{3}$ ionization energies between tin and lead $\left[E_{3}(\mathrm{~Pb})=31.94\right.$ $\mathrm{eV}$ and $\left.E_{3}(\mathrm{Sn})=30.5 \mathrm{eV}\right]$, the effect of the additional polarizability (presence of filled diffuse $d$ and $f$ orbitals below the valence electrons in $\mathrm{Pb})$, and the distortions of the $\mathrm{M}-\mathrm{X}(\mathrm{M}$ $=\mathrm{Sn}, \mathrm{Pb})$ octahedra. A different degree of tilting of the $\mathrm{MBr}_{6}$ octahedra is observed for $\mathrm{Cs}_{2} \mathrm{GPb}_{2} \mathrm{Br}_{7}$ and III (Figure S14), with stronger deviations from the ideal $180^{\circ}$ for the lead compound. Interestingly, despite the different tilts of the octahedra, the angles are in the end compensated for in a manner that gives the required amount of space for guanidinium and cesium cations. Figure $4 \mathrm{e}, \mathrm{f}$ reports the computed band structures for the leadbased analogues of compounds II and III that share many similarities with the tin-based layered perovskites (Figure 4a,c). For both II and III, the predicted electronic band gaps follow the same trends as the abovementioned experimental results. For instance, the band gap increases from $1.04(\mathrm{Sn})$ to $1.55 \mathrm{eV}(\mathrm{Pb})$ for II and from $0.84(\mathrm{Sn})$ to $1.32 \mathrm{eV}(\mathrm{Pb})$ for III.

Both $\mathrm{CsSnBr}_{3}$ and I are luminescent at RT, unlike II and III. The PL of $\mathrm{G}_{2} \mathrm{SnBr}_{4}$ (I) at RT is characterized by a broad emission band (Figure 1d) with an FWHM of $\sim 121 \mathrm{~nm}, 2 \%$ PLQY, and a large Stokes shift of $\sim 208 \mathrm{~nm}$. At $77 \mathrm{~K}$, the PLQY reaches $75 \pm 5 \%$ and the PL band narrows down (FWHM $\sim 72$ $\mathrm{nm}$ ) while retaining the same peak position at $557 \mathrm{~nm}$ with a Stokes shift of $233 \mathrm{~nm}$. Additionally, the PL excitation spectrum at $77 \mathrm{~K}$ is blue-shifted compared to that at RT. $\mathrm{CsSnBr}_{3}$ exhibits a PL maximum at $1.70 \mathrm{eV}$ (Figure $1 \mathrm{~d}$ ) at $\mathrm{RT}$, which is consistent with the literature value. ${ }^{57}$ In the $\mathrm{PL}$ spectrum of $\mathrm{CsSnBr}_{3}$, a shoulder was observed at the higher energy side, which seems to originate from an amorphous or nanocrystalline $\mathrm{CsSnBr}_{3}$ impurity. ${ }^{58}$ A blue shift of the emission bands of $\mathrm{CsSnBr}_{3}$ was observed when the temperature increased from 228 to $383 \mathrm{~K}$ (Figure S15). This trend is consistent with previous temperature-dependent PL theoretical and experimental studies and is explained by the lattice expansion upon heating and local displacements of the $\mathrm{Sn}$ (II) cation. ${ }^{56,59,60}$ Large differences in the width of the PL bands and Stokes shifts for $\mathrm{G}_{2} \mathrm{SnBr}_{4}$ (I) and $\mathrm{CsSnBr}_{3}$ indicate different radiative processes in these compounds. Time-resolved PL measurements (Figure 1e) yielded a PL lifetime of $0.4 \mathrm{~ns}$ for $\mathrm{CsSnBr}_{3}$ and $18 \mathrm{~ns}$ in compound I. The short lifetime, the small Stokes shift, and the narrow PL band attest to the excitonic nature of the radiative transition in $\mathrm{CsSnBr}_{3}$. On the contrary, the longer PL lifetime and larger Stokes shift and broader FWHM point to emission via self-trapped excitons in compound I (Figure 1f). Importantly, the PL lifetime in $1 \mathrm{D} \mathrm{G}_{2} \mathrm{SnBr}_{4}$ is much faster (18 ns) than that commonly found in OD Sn(II) halides $\left(10^{2}-10^{3} \mathrm{~ns}\right.$ for bromide) at RT. $^{6-8,27}$ This might eventually lead to a practical advantage, for instance, in the context of applications such as white-light sources, ${ }^{7,8,26}$ as the achievable saturated emission brightness scales with the PL lifetime.
For II and III, which are structurally more rigid and exhibit a delocalized electronic structure that reduces the propensity to form self-trapped excitons, the PL was measurable only at cryogenic temperatures $(5-120 \mathrm{~K}$, Figure $3 \mathrm{e})$. At $5 \mathrm{~K}$, the main band peaks are at $517 \mathrm{~nm}$ with an additional emission band around $577 \mathrm{~nm}$. A broad emission band above $700 \mathrm{~nm}$ is also visible. Due to the very low PLQY and presence of different phases within the same sample, it is difficult to draw solid conclusions. Yet, one can attribute the main emission bands to free excitons or self-trapped excitons with low stabilization energy (due to hindered structural distortion as compared to $0 \mathrm{D}$ and $1 \mathrm{D}$ compounds). Finally, the lowest energy band might stem from surface defects. By increasing the temperature, the PL intensity quickly drops due to the activation of nonradiative processes. We have performed time-resolved PL measurements with a streak camera system, and the results are displayed in Figure $3 \mathrm{f}$. The measured sub-100 ps decay times and their dependence on temperature attest to the presence of nonradiative processes, which efficiently quench radiative recombination.

In conclusion, we presented a highly luminescent $1 \mathrm{D}$ compound $\mathrm{G}_{2} \mathrm{SnBr}_{4}$ at $77 \mathrm{~K}$, as well as layered $2 \mathrm{D}$ perovskites $\mathrm{CsGSnBr}_{4}$ and $\mathrm{Cs}_{2} \mathrm{GSn}_{2} \mathrm{Br}_{7}$. In $\mathrm{G}_{2} \mathrm{SnBr}_{4}$, the $\mathrm{Sn}$ (II) lone pair is stereoactive and influences the coordination environment of $\mathrm{Sn}(\mathrm{II}) . \mathrm{G}_{2} \mathrm{SnBr}_{4}$ is a luminescent compound with broadband emission from self-trapped excitonic states that are enabled by the soft lattice and electronic localization. This emission is characterized by a PLQY of $2 \%$ at RT and $75 \pm 5 \%$ at $77 \mathrm{~K}$. $\mathrm{G}_{2} \mathrm{SnBr}_{4}$ does not thermally decompose until $300{ }^{\circ} \mathrm{C}$. The addition of cesium to the $\mathrm{G}-\mathrm{Sn}-\mathrm{Br}$ system promotes the formation of structurally more rigid, layered perovskite compounds, obscuring the formation of self-trapped excitons but leading to a delocalized electronic structure. $\mathrm{Cs}_{2} \mathrm{GSn}_{2} \mathrm{Br}_{7}$ has a smaller band gap than its lead analogue, $\mathrm{Cs}_{2} \mathrm{GPb}_{2} \mathrm{Br}_{7}$, due to the difference in $E_{3}$ ionization energies of tin and lead, higher electronegativity of $\mathrm{Pb}$, and the different degree of structural distortion. Lastly, in-plane electronic coupling is anisotropic as a result of the planar shape of the guanidinium cation, which leads to significant octahedral out-of-plane tilting in only one of the two directions.

\section{ASSOCIATED CONTENT}

\section{Supporting Information}

The Supporting Information is available free of charge on the ACS Publications website at DOI: 10.1021/acs.chemmater.9b00038.

Crystallographic details of $\mathrm{G}_{2} \mathrm{SnBr}_{4}$ (CIF)

Crystallographic details of $\mathrm{Cs}_{2} \mathrm{GSn}_{2} \mathrm{Br}_{7}$ (CIF)

Crystallographic details of $\mathrm{CsGSnBr}_{4}$ (CIF)

Crystallographic details of $\mathrm{Cs}_{8} \mathrm{Sn}_{6} \mathrm{Br}_{13} \mathrm{I}_{7}$ (CIF)

Single crystal and powder XRD, thermal analysis, optical characterization, and EDX spectroscopy and electronic structure calculations (PDF)

\section{AUTHOR INFORMATION}

\section{Corresponding Author}

*E-mail: mvkovalenko@ethz.ch. ORCID $\odot$

Sergii Yakunin: 0000-0002-6409-0565

Frank Krumeich: 0000-0001-5625-1536

Mikaël Kepenekian: 0000-0001-5192-5896

Jacky Even: 0000-0002-4607-3390 
Claudine Katan: 0000-0002-2017-5823

Maksym V. Kovalenko: 0000-0002-6396-8938

Notes

The authors declare no competing financial interest.

\section{ACKNOWLEDGMENTS}

The authors thank IBM-Zurich Research, in particular, Dr. T. Stöferle and Dr. R.F. Mahrt, for support with low-temperature PL experiments. This work was financially supported by the European Union through the FP7 (ERC Starting Grant NANOSOLID, GA No. 306733). DFT calculations were performed at the Institut des Sciences Chimiques de Rennes, which received funding from Agence Nationale pour la Recherche (TRANSHYPERO project), and the work was granted access to the HPC resources of TGCC/CINES/IDRIS under the allocation 2018-A0030907682 made by GENCI. J.E. is a senior member of Institut Universitaire de France. The work at Institut FOTON was supported by Agence Nationale pour la Recherche (SupersansPlomb project).

\section{REFERENCES}

(1) Stoumpos, C. C.; Mao, L.; Malliakas, C. D.; Kanatzidis, M. G. Structure-band gap relationships in hexagonal polytypes and lowdimensional structures of hybrid tin iodide perovskites. Inorg. Chem. 2017, 56, 56-73.

(2) Xu, Z.; Mitzi, D. B. $\mathrm{SnI}_{4}{ }^{2-}$-based hybrid perovskites templated by multiple organic cations: combining organic functionalities through noncovalent interactions. Chem. Mater. 2003, 15, 3632-3637.

(3) Zhou, C.; Tian, Y.; Wang, M.; Rose, A.; Besara, T.; Doyle, N. K.; Yuan, Z.; Wang, J. C.; Clark, R.; Hu, Y.; Siegrist, T.; Lin, S.; Ma, B. Lowdimensional organic tin bromide perovskites and their photoinduced structural transformation. Angew. Chem. Int. Ed. 2017, 56, 9018-9022.

(4) Herrmann, H.; Walter, P.; Kaifer, E.; Himmel, H.-J. Incorporation of a redox-active bis(guanidine) in low-dimensional tin and lead iodide structures. Eur. J. Inorg. Chem. 2017, 2017, 5539-5544.

(5) Lode, C.; Krautscheid, H. Schwache Sn...I-wechselwirkungen in den kristallstrukturen der iodostannate $\left[\mathrm{SnI}_{4}\right]_{2}-$ und $\left[\mathrm{SnI}_{3}\right]$-. Z. Anorg. Allg. Chem. 2000, 626, 326-331.

(6) Zhou, C.; Lin, H.; Shi, H.; Tian, Y.; Pak, C.; Shatruk, M.; Zhou, Y.; Djurovich, P.; Du, M. H.; Ma, B. A zero-dimensional organic seesawshaped tin bromide with highly efficient strongly stokes-shifted deepred emission. Angew. Chem. Int. Ed. 2017, 57, 1021-1024.

(7) Zhou, C.; Tian, Y.; Yuan, Z.; Lin, H.; Chen, B.; Clark, R.; Dilbeck, T.; Zhou, Y.; Hurley, J.; Neu, J.; Besara, T.; Siegrist, T.; Djurovich, P.; $\mathrm{Ma}, \mathrm{B}$. Highly efficient broadband yellow phosphor based on zerodimensional tin mixed-halide perovskite. ACS Appl. Mater. Interfaces 2017, 9, 44579-44583.

(8) Zhou, C.; Lin, H.; Tian, Y.; Yuan, Z.; Clark, R.; Chen, B.; van de Burgt, L. J.; Wang, J. C.; Zhou, Y.; Hanson, K.; Meisner, Q. J.; Neu, J.; Besara, T.; Siegrist, T.; Lambers, E.; Djurovich, P.; Ma, B. Luminescent zero-dimensional organic metal halide hybrids with near-unity quantum efficiency. Chem. Sci. 2018, 9, 586-593.

(9) Hao, F.; Stoumpos, C. C.; Guo, P.; Zhou, N.; Marks, T. J.; Chang, R. P. H.; Kanatzidis, M. G. Solvent-mediated crystallization of $\mathrm{CH}_{3} \mathrm{NH}_{3} \mathrm{SnI}_{3}$ films for heterojunction depleted perovskite solar cells. J. Am. Chem. Soc. 2015, 137, 11445-11452.

(10) Noel, N. K.; Stranks, S. D.; Abate, A.; Wehrenfennig, C.; Guarnera, S.; Haghighirad, A.-A.; Sadhanala, A.; Eperon, G. E.; Pathak, S. K.; Johnston, M. B.; Petrozza, A.; Herz, L. M.; Snaith, H. J. Lead-free organic-inorganic tin halide perovskites for photovoltaic applications. Energy Environ. Sci. 2014, 7, 3061-3068.

(11) Zhu, H. L.; Liang, Z.; Huo, Z.; Ng, W. K.; Mao, J.; Wong, K. S.; Yin, W.-J.; Choy, W. C. H. Low-bandgap methylammonium-rubidium cation Sn-rich perovskites for efficient ultraviolet-visible-near infrared photodetectors. Adv. Funct. Mater. 2018, 28, 1706068.
(12) Stoumpos, C. C.; Malliakas, C. D.; Kanatzidis, M. G. Semiconducting tin and lead iodide perovskites with organic cations: phase transitions, high mobilities, and near-infrared photoluminescent properties. Inorg. Chem. 2013, 52, 9019-9038.

(13) Mitzi, D. B.; Wang, S.; Feild, C. A.; Chess, C. A.; Guloy, A. M. Conducting layered organic-inorganic halides containing $\langle 110\rangle$ oriented perovskite sheets. Science 1995, 267, 1473-1476.

(14) Guan, J.; Tang, Z.; Guloy, A. M. $\alpha$ - $\left[\mathrm{NH}_{3}\left(\mathrm{CH}_{2}\right)_{5} \mathrm{NH}_{3}\right] \mathrm{SnI}_{4}$ : a new layered perovskite structure. Chem. Commun. 1999, 1833-1834.

(15) Yamada, K.; Kuranaga, Y.; Ueda, K.; Goto, S.; Okuda, T.; Furukawa, Y. Phase transition and electric conductivity of $\mathrm{ASnCl}_{3}(\mathrm{~A}=$ Cs and $\mathrm{CH}_{3} \mathrm{NH}_{3}$ ). Bull. Chem. Soc. Jpn. 1998, 71, 127-134.

(16) Yamada, K.; Nakada, K.; Takeuchi, Y.; Nawa, K.; Yamane, Y. Tunable perovskite semiconductor $\mathrm{CH}_{3} \mathrm{NH}_{3} \mathrm{SnX}_{3}$ (X: $\mathrm{Cl}, \mathrm{Br}$, or I) characterized by X-ray and DTA. Bull. Chem. Soc. Jpn. 2011, 84, 926932.

(17) Dang, Y.; Zhong, C.; Zhang, G.; Ju, D.; Wang, L.; Xia, S.; Xia, H.; Tao, X. Crystallographic investigations into properties of acentric hybrid perovskite single crystals $\mathrm{NH}\left(\mathrm{CH}_{3}\right)_{3} \mathrm{SnX}_{3}(\mathrm{X}=\mathrm{Cl}, \mathrm{Br})$. Chem. Mater. 2016, 28, 6968-6974.

(18) Chouaib, H.; Kamoun, S.; Costa, L. C.; Graça, M. P. F. Synthesis, crystal structure and electrical properties of N,N-dimethylanilinium trichloridostannate (II): $\left(\mathrm{C}_{8} \mathrm{H}_{12} \mathrm{~N}\right) \mathrm{SnCl}_{3}$. J. Mol. Struct. 2015, 1102, 71-80.

(19) Lode, C.; Krautscheid, H.; Müller, U. $\left[\mathrm{C}_{3} \mathrm{H}_{7} \mathrm{~N}\left(\mathrm{C}_{2} \mathrm{H}_{4}\right)_{3} \mathrm{NC}_{3} \mathrm{H}_{7}\right]_{2}$ $\infty 1\left[\mathrm{Sn}_{4} \mathrm{I}_{12}\right]$ - ein iodostannat aus verknüpften SnI5-pyramiden. $Z$. Anorg. Allg. Chem. 2005, 631, 587-591.

(20) Raptopoulou, C. P.; Terzis, A.; Mousdis, G. A.; Papavassiliou, G. C. Preparation, structure and optical properties of $\left[\mathrm{CH}_{3} \mathrm{SC}\right.$ $\left.\left(\mathrm{NH}_{2}\right)_{2}\right]_{3} \mathrm{SnI}_{5}, \quad\left[\mathrm{CH}_{3} \mathrm{SC}\left(\mathrm{NH}_{2}\right)_{2}\right]\left[\mathrm{HSC}\left(\mathrm{NH}_{2}\right)_{2}\right] \mathrm{SnBr}{ }_{4}$, $\left(\mathrm{CH}_{3} \mathrm{C}_{5} \mathrm{H}_{4} \mathrm{NCH}_{3}\right) \mathrm{PbBr}_{3}$, and $\left[\mathrm{C}_{6} \mathrm{H}_{5} \mathrm{CH}_{2} \mathrm{SC}\left(\mathrm{NH}_{2}\right)_{2}\right]_{4} \mathrm{~Pb}_{3} \mathrm{I}_{10}$. Z. Naturforsch. B Chem. 2002, 57, 645.

(21) Knutson, J. L.; Martin, J. D.; Mitzi, D. B. Tuning the band gap in hybrid tin iodide perovskite semiconductors using structural templating. Inorg. Chem. 2005, 44, 4699-4705.

(22) Papavassiliou, G. C.; Koutselas, I. B.; Terzis, A.; Whangbo, M. H. Structural and electronic properties of the natural quantum-well system $\left(\mathrm{C}_{6} \mathrm{H}_{5} \mathrm{CH}_{2} \mathrm{CH}_{2} \mathrm{NH}_{3}\right)_{2} \mathrm{SnI}_{4}$. Solid State Commun. 1994, 91, 695-698.

(23) Xu, Z.; Mitzi, D. B.; Dimitrakopoulos, C. D.; Maxcy, K. R. Semiconducting perovskites $\left(2-\mathrm{XC}_{6} \mathrm{H}_{4} \mathrm{C}_{2} \mathrm{H}_{4} \mathrm{NH}_{3}\right)_{2} \mathrm{SnI}_{4}(\mathrm{X}=\mathrm{F}, \mathrm{Cl}, \mathrm{Br})$ : steric interaction between the organic and inorganic layers. Inorg. Chem. 2003, 42, 2031-2039.

(24) Lanzetta, L.; Marin-Beloqui, J. M.; Sanchez-Molina, I.; Ding, D.; Haque, S. A. Two-dimensional organic tin halide perovskites with tunable visible emission and their use in light-emitting devices. ACS Energy Lett. 2017, 2, 1662-1668.

(25) Han, D.; Shi, H.; Ming, W.; Zhou, C.; Ma, B.; Saparov, B.; Ma, Y.Z.; Chen, S.; Du, M.-H. Unraveling luminescence mechanisms in zerodimensional halide perovskites. J. Mater. Chem. C 2018, 6, 6398-6405.

(26) Luo, J.; Wang, X.; Li, S.; Liu, J.; Guo, Y.; Niu, G.; Yao, L.; Fu, Y.; Gao, L.; Dong, Q.; Zhao, C.; Leng, M.; Ma, F.; Liang, W.; Wang, L.; Jin, S.; Han, J.; Zhang, L.; Etheridge, J.; Wang, J.; Yan, Y.; Sargent, E. H.; Tang, J. Efficient and stable emission of warm-white light from lead-free halide double perovskites. Nature 2018, 563, 541-545.

(27) Benin, B. M.; Dirin, D. N.; Morad, V.; Wörle, M.; Yakunin, S.; Rainò, G.; Nazarenko, O.; Fischer, M.; Infante, I.; Kovalenko, M. V. Highly emissive self-trapped excitons in fully inorganic zero-dimensional tin halides. Angew. Chem., Int. Ed. 2018, 57, 11329-11333.

(28) Zhou, C.; Worku, M.; Neu, J.; Lin, H.; Tian, Y.; Lee, S.; Zhou, Y.; Han, D.; Chen, S.; Hao, A.; Djurovich, P. I.; Siegrist, T.; Du, M.-H.; Ma, B. Facile preparation of light emitting organic metal halide crystals with near-unity quantum efficiency. Chem. Mater. 2018, 30, 2374-2378.

(29) Parrott, E. S.; Milot, R. L.; Stergiopoulos, T.; Snaith, H. J.; Johnston, M. B.; Herz, L. M. Effect of structural phase transition on charge-carrier lifetimes and defects in $\mathrm{CH}_{3} \mathrm{NH}_{3} \mathrm{SnI}_{3}$ Perovskite. J. Phys. Chem. Lett. 2016, 7, 1321-1326.

(30) Daub, M.; Haber, C.; Hillebrecht, H. Synthesis, crystal structures, optical properties and phase transitions of the layered guanidinium- 
based hybrid perovskites $\left(\mathrm{C}\left(\mathrm{NH}_{2}\right)_{3}\right)_{2} \mathrm{MI}_{4} ; \mathrm{M}=\mathrm{Sn}$, Pb. Eur. J. Inorg. Chem. 2017, 2017, 1120-1126.

(31) Kieslich, G.; Sun, S.; Cheetham, A. K. An extended Tolerance Factor approach for organic-inorganic perovskites. Chem. Sci. 2015, 6, 3430-3433.

(32) Pauling, L. The nature of the chemical bond and the structure of molecules and crystals: An Introduction to Mode. Cornell University Press: Ithaca, New York 1940, 286-288.

(33) Russell, V. A.; Ward, M. D. Molecular crystals with dimensionally controlled hydrogen-bonded nanostructures. Chem. Mater. 1996, 8, 1654-1666.

(34) Szafrański, M.; Ståhl, K. Pressure-induced decoupling of the order-disorder and displacive contributions to the phase transition in diguanidinium tetrachlorostannate. Phys. Rev. B 2000, 62, 8787-8793.

(35) Szafrański, M.; Ståhl, K. Crystal structure and phase transitions in perovskite-like $\mathrm{C}\left(\mathrm{NH}_{2}\right)_{3} \mathrm{SnCl}_{3}$. J. Solid State Chem. 2007, 180, 22092215.

(36) Yamada, K.; Funabiki, S.; Horimoto, H.; Matsui, T.; Okuda, T.; Ichiba, S. Structural phase transitions of the polymorphs of $\mathrm{CsSnI}_{3}$ by means of rietveld analysis of the X-ray diffraction. Chem. Lett. 1991, 20, 801-804.

(37) Brucker APEX3 v2017.3-0. Bruker AXS Inc., Madison, Wisconsin, USA, 2016.

(38) Sheldrick, G. M. A short history of SHELX. Acta Crystallogr. A 2008, 64, 112-122.

(39) Sheldrick, G. M. Crystal structure refinement with SHELXL. Acta Crystallogr. C 2015, 71, 3-8.

(40) Dolomanov, O. V.; Bourhis, L. J.; Gildea, R. J.; Howard, J. A. K.; Puschmann, H. OLEX2: a complete structure solution, refinement and analysis program. J. Appl. Crystallogr. 2009, 42, 339-341.

(41) Soler, J. M.; Artacho, E.; Gale, J. D.; García, A.; Junquera, J.; Ordejón, P.; Sánchez-Portal, D. The SIESTA method for ab initio order-N materials simulation. J. Phys. Condens. Matter. 2002, 14, 2745. (42) Artacho, E.; Anglada, E.; Diéguez, O.; Gale, J. D.; García, A.; Junquera, J.; Martin, J. D.; Ordejón, P.; Pruneda, J. M.; Sánchez-Portal, D.; Soler, J. M. The SIESTA method; developments and applicability. J. Phys. Condens. Matter. 2008, 20, 064208.

(43) Perdew, J. P.; Burke, K.; Ernzerhof, M. Generalized gradient approximation made simple. Phys. Rev. Lett. 1996, 77, 3865-3868.

(44) Troullier, N.; Martins, J. L. Efficient pseudopotentials for planewave calculations. Phys. Rev. B 1991, 43, 1993-2006.

(45) Artacho, E.; Sánchez-Portal, D.; Ordejón, P.; García, A.; Soler, J. M. Linear-scaling ab-initio calculations for large and complex systems. Phys. Stat. Sol. B 1999, 215, 809-817.

(46) Fernández-Seivane, L.; Oliveira, M. A.; Sanvito, S.; Ferrer, J. Onsite approximation for spin-orbit coupling in linear combination of atomic orbitals density functional methods. J. Phys. Condens. Matter. 2006, 18, 7999.

(47) Andersson, J. On the crystal structure of $\mathrm{NH}_{4} \mathrm{SnBr}_{3} \times \mathrm{H}_{2} \mathrm{O}$. Acta Chem. Scand. 1976, 30a, 229-229.

(48) Nazarenko, O.; Kotyrba, M. R.; Wörle, M.; Cuervo-Reyes, E.; Yakunin, S.; Kovalenko, M. V. Luminescent and photoconductive layered lead halide perovskite compounds comprising mixtures of cesium and guanidinium cations. Inorg. Chem. 2017, 56, 11552-11564.

(49) Donaldson, J. D.; Silver, J.; Hadjiminolis, S.; Ross, S. D. Effects of the presence of valence-shell non-bonding electron pairs on the properties and structures of caesium tin(II) bromides and of related antimony and tellurium compounds. J. Chem. Soc., Dalton Trans. 1975, $15,1500-1506$.

(50) Barrett, J.; Bird, S. R. A.; Donaldson, J. D.; Silver, J. The Mössbauer effect in tin(II) compounds. Part XI. The spectra of cubic trihalogenostannates(II). J. Chem. Soc. A 1971, 3105-3108.

(51) Scaife, D. E.; Weller, P. F.; Fisher, W. G. Crystal preparation and properties of cesium tin(II) trihalides. J. Solid State Chem. 1974, 9, 308-314.

(52) Mauersberger, P.; Huber, F. Structure of caesium triiodostannate(II). Acta Crystallogr. B 1980, 36, 683-684.
(53) Trots, D. M.; Myagkota, S. V. High-temperature structural evolution of caesium and rubidium triiodoplumbates. J. Phys. Chem. Solids 2008, 69, 2520-2526.

(54) Li, J.; Stoumpos, C. C.; Trimarchi, G. G.; Chung, I.; Mao, L.; Chen, M.; Wasielewski, M. R.; Wang, L.; Kanatzidis, M. G. Air-stable direct bandgap perovskite semiconductors: all-inorganic tin-based heteroleptic halides $\mathrm{A}_{\mathrm{x}} \mathrm{SnCl}_{\mathrm{y}} \mathrm{I}_{\mathrm{z}}(\mathrm{A}=\mathrm{Cs}, \mathrm{Rb})$. Chem. Mater. 2018, 30, 4847-4856.

(55) Even, J.; Pedesseau, L.; Katan, C. Analysis of multivalley and multibandgap absorption and enhancement of free carriers related to exciton screening in hybrid perovskites. J. Phys. Chem. C 2014, 118, 11566-11572.

(56) Clark, S. J.; Flint, C. D.; Donaldson, J. D. Luminescence and electrical conductivity of $\mathrm{CsSnBr}_{3}$, and related phases. J. Phys. Chem. Solids 1981, 42, 133-135.

(57) Lorena, G. S.; Hasegawa, H.; Takahashi, Y.; Harada, J.; Inabe, T. Hole doping of tin bromide and lead bromide organic-inorganic hybrid semiconductors. Chem. Lett. 2014, 43, 1535-1537.

(58) Jellicoe, T. C.; Richter, J. M.; Glass, H. F. J.; Tabachnyk, M.; Brady, R.; Dutton, S. E.; Rao, A.; Friend, R. H.; Credgington, D.; Greenham, N. C.; Böhm, M. L. Synthesis and optical properties of leadfree cesium tin halide perovskite nanocrystals. J. Am. Chem. Soc. 2016, 138, 2941-2944.

(59) Fabini, D. H.; Laurita, G.; Bechtel, J. S.; Stoumpos, C. C.; Evans, H. A.; Kontos, A. G.; Raptis, Y. S.; Falaras, P.; Van der Ven, A.; Kanatzidis, M. G.; Seshadri, R. Dynamic stereochemical activity of the $\mathrm{Sn}^{2+}$ lone pair in perovskite $\mathrm{CsSnBr}_{3}$. J. Am. Chem. Soc. 2016, 138, $11820-11832$.

(60) Voloshinovskii, A. S.; Mikhailik, V. B.; Myagkota, S. V.; Ostrovskii, I. P.; Pidzyrailo, N. S. Electronic states and luminescent properties of a cesium tin bromide $\left(\mathrm{CsSnBr}_{3}\right)$ crystal. Opt. Spektrosk. 1992, 72, 902-4. 